\title{
Effect of guar gum on gastric emptying of test meals of varying energy content in growing pigs
}

\author{
BY ANNA L. RAINBIRD* \\ National Institute for Research in Dairying $\dagger$, Shinfield, Reading, Berks RG2 9AT
}

(Received 15 November 1984 - Accepted 16 July 1985)

\begin{abstract}
1. Existing information on whether the action of guar gum in decreasing postprandial blood glucose concentrations is due, at least in part, to a reduced rate of gastric emptying is conflicting, possibly because three types of test meals have been used. In order to test whether the type of test meal used influences the action of guar gum, these three types of meal were compared, either without or with guar gum, in growing pigs. The meals were: a high-energy meal (HEM), a low-energy milky drink (LEMD) and a glucose drink (GD).

2. Six pigs were prepared with a simple gastric cannula which allowed complete removal of the stomach contents just before or $0 \cdot 5,1,2$ or $4 \mathrm{~h}$ after feeding.

3. The three types of test meal without guar gum gave rise to very different postprandial profiles of gastric pH and of digesta and dry matter (DM) emptying from the stomach.

4. Addition of guar gum to the GD significantly raised gastric $\mathrm{pH}$ at 0.5 and $1 \mathrm{~h}$ after feeding but, when it was added to HEM, gastric $\mathrm{pH}$ was only significantly raised $4 \mathrm{~h}$ after feeding. No significant effect on gastric $\mathrm{pH}$ was seen when guar gum was added to LEMD.

5. Although addition of guar gum to GD had no significant effect on the emptying of digesta from the stomach, when added to HEM the rate of emptying of digesta was significantly reduced 1,2 and $4 \mathrm{~h}$ after feeding. Addition of guar gum to LEMD only significantly increased the amount of digesta remaining in the stomach $2 \mathrm{~h}$ after feeding.

6. There was no significant effect on the emptying of DM from the stomach when guar gum was added to either HEM or LEMD. However, addition of guar gum to GD significantly reduced the mean rate of emptying of DM $0 \cdot 5 \mathrm{~h}$ after feeding.

7. Addition of guar gum to either LEMD or GD had no significant effect on the DM concentration of the evacuated gastric digesta. However, addition of guar gum to HEM significantly lowered the DM concentration of the evacuated gastric digesta 1,2 and $4 \mathrm{~h}$ after feeding.

8. It was concluded that differences in test meal composition and also in the methods used to measure gastric emptying could account for the discrepancies previously reported. The results suggest that although guar gum may reduce the rate of gastric emptying under some conditions, this is unlikely to be the only mechanism by which it acts.
\end{abstract}

Although the beneficial effects of guar gum on glucose tolerance (in particular, by reducing postprandial blood glucose levels) in normal and diabetic man are well established, its detailed mode of action remains unclear. Jenkins et al. (1978) suggested that these effects might be the result of a reduced rate of gastric emptying but studies designed to investigate this hypothesis have given conflicting results. We have recently found that guar gum had little effect on the gastric emptying rate of dry matter (DM) (and thus of glucose) from high-energy meals in pigs prepared with a simple gastric cannula (Rainbird \& Low, 1986). This contrasts with the reductions caused by guar gum in the gastric emptying rate of (1) a glucose solution given by orogastric intubation to rats (Leeds et al. 1979), (2) a milky drink consumed by obese humans (Wilmshurst \& Crawley, 1980) and (3) a glucose drink consumed by normal humans (Jarjis et al. 1984). Leeds et al. (1979) measured the residual gastric contents after killing the rats, Wilmshurst \& Crawley (1980) measured the appearance of ${ }^{24} \mathrm{Na}$ marker added to the meal in the blood reaching the head, while Jarjis et al. (1984) measured the amount of ${ }^{99 \mathrm{~m}} \mathrm{Tc}$ marker remaining in the stomach. These differences in the effects of guar gum on gastric emptying could have been due to differences

* Present address: Waltham Centre for Pet Nutrition, Freeby Lane, Waltham-on-the-Wolds, Melton Mowbray, Leics LE14 4RS.

$\dagger$ Now the Animal and Grassland Research Institute, Shinfield, Reading, Berks RG2 9AQ. 
in the composition of the meal, the type and amount of guar gum, the volume of the meal, the species studied or the measurement technique.

In an attempt to clarify this confusing picture the present study was designed to compare the effects of guar gum on the rate of gastric emptying of the three types of test meal used in the studies referred to previously. The comparisons were made in growing pigs fitted with a simple gastric cannula to allow total collection of gastric digesta at different times after consumption of the meal.

\section{EXPERIMENTAL METHODS}

Animals and housing

Six male Large White $\times$ Landrace pigs, initially of $30 \mathrm{~kg}$ live weight, were used. They were surgically prepared with a simple gastric cannula as described by Low et al. (1985). The animals were housed in metabolism crates throughout the experiment.

\section{Treatments}

Three types of test meal were compared: (a) a high-energy meal (HEM), $(b)$ a low-energy milky drink (LEMD) and (c) a glucose drink (GD). Each was given without or with guar gum (Meyprogat 150; Meyhall Chemical (UK) Ltd, Wirral, Merseyside). When guar gum was added to meals HEM, LEMD and GD, they were coded HEMG, LEMDG and GDG respectively. The test meals were made each day $15 \mathrm{~min}$ before feeding. The LEMD, LEMDG, GD and GDG were given only on the mornings of collection days. Each of the six treatments was given to each pig for 1 week in a Latin-square design. HEM was given without or with $60 \mathrm{~g}$ guar gum $/ \mathrm{kg}$ air-dry diet and fed at a level of $32.5 \mathrm{~g} / \mathrm{kg}$ body-weight per $\mathrm{d}$ in two equal meals mixed with water $(1: 2 \cdot 5, \mathrm{w} / \mathrm{v})$ before feeding as in the previous studies (Rainbird \& Low, 1986).

Because Leeds et al. (1979) had shown that addition of guar gum to a glucose drink reduced the rate of gastric emptying in rats, the same glucose drink was included as a treatment in the present study. The amounts of glucose and guar gum and the volume of the drink used in the present experiment were calculated by scaling up the amounts used by Leeds et al. (1979) in rats in direct proportion to live weight (using the predicted weight of the pigs in the middle of the experiment); thus GD contained $125 \mathrm{~g}$ glucose dissolved in 1 litre tap water, without or with $20 \mathrm{~g}$ guar gum. Similar test meals (usually of $50 \mathrm{~g}$ glucose and $400 \mathrm{ml}$ water) have been widely used to examine the effects of different types of dietary fibre on glucose tolerance in man (e.g. Jenkins et al. 1978).

The LEMD used in the present study was first used by Wilmshurst \& Crawley (1980) who found a reduction in the rate of gastric emptying following addition of guar gum when the drink was given to obese human subjects. The LEMD was used in the present study as it had the highest DM content of all the test meals previously used in studies of the effects of guar gum on gastric emptying in any species; it was intermediate between GD and HEM in this respect. Wilmshurst \& Crawley (1980) used $200 \mathrm{ml}$ LEMD without or with $2 \mathrm{~g}$ guar gum, but in the present study the volume used was increased to 1 litre so that comparisons with the same volume of GD could be made. Furthermore, the errors involved in using a volume as small as $200 \mathrm{ml}$ were reduced by using a larger volume. The amount of guar gum used in the present study was $10 \mathrm{~g} / \mathrm{l}$, i.e. the same concentration used by Wilmshurst \& Crawley (1980).

\section{Animal feeding}

During the experiment the animals were weighed every Friday at 14.00 hours. They were given HEM (described previously) on a scale based on their live weight $(32.5 \mathrm{~g} / \mathrm{kg}$ body-weight per d), except on those mornings when they were allocated GD or LEMD. 
Table 1. Composition of test meals

\begin{tabular}{|c|c|c|c|c|c|}
\hline \multicolumn{2}{|c|}{$\begin{array}{l}\text { High-energy meal* } \\
(\mathrm{g} / \mathrm{kg})\end{array}$} & \multicolumn{2}{|c|}{$\begin{array}{l}\text { Glucose drink } \dagger \\
(\mathrm{g} / \mathrm{l})\end{array}$} & \multicolumn{2}{|c|}{$\begin{array}{l}\text { Low-energy milky drink } \uparrow \\
(\mathrm{g} / \mathrm{l})\end{array}$} \\
\hline Maize starch & $550 \cdot 9$ & Glucose** & $125 \cdot 0$ & Homogenized milk & $885 \cdot 0$ \\
\hline Soya-bean oil + & $80 \cdot 0$ & Water & $1000 \cdot 0$ & Caloreent† & $52 \cdot 5$ \\
\hline Megalac 958 (tallow) & $80 \cdot 0$ & & & Double cream & 52.5 \\
\hline Casein & $180 \cdot 0$ & & & Cocoa powder & $10 \cdot 0$ \\
\hline Solkafloc & $60 \cdot 0$ & & & & \\
\hline $\begin{array}{l}\text { Mineral and } \\
\text { vitamin mix } \|\end{array}$ & $49 \cdot 1$ & & & & \\
\hline Guar gum $\uparrow$ & $60 \cdot 0$ & & $20 \cdot 0$ & & $10 \cdot 0$ \\
\hline $\begin{array}{l}\text { Gross energy } \\
\text { (calculated) }\end{array}$ & $16.72 \mathrm{MJ} / \mathrm{kg}$ & & $1.88 \mathrm{MJ} / 1$ & & $4 \cdot 31 \mathrm{MJ} / 1$ \\
\hline
\end{tabular}

* Mixed with water $(1: 2.5, \mathrm{w} / \mathrm{v})$ before consumption, fed at $32.5 \mathrm{~g} / \mathrm{kg}$ body-weight per $\mathrm{d}$ in two equal meals.

+1 litre of the drinks was given.

\# Sainsbury's soya oil; J. Sainsbury Ltd, London.

$\S$ Volac Ltd, Royston, Herts.

$\|$ Composition given by Rainbird \& Low (1985).

T Meyprogat 150; Meyhall Chemical (UK) Ltd, Wirral, Merseyside.

** Glucose monohydrate; SAS Chemicals Ltd, London.

t† Caloreen (Roussel Laboratories Ltd, Wembley Park, Middlesex) is a glucose polymer produced from maize starch by enzymic hydrolysis. It has no more than $3 \%$ of carbohydrate as free glucose, a mean chain length of 5 units and approximately $80 \%$ of the linkages in the 1,4 configuration. It contains no protein or fat, it is $96 \%$ carbohydrate, the remainder being minerals and water.

The air-dry diet was mixed with water $(1: 2 \cdot 5, \mathrm{w} / \mathrm{v}) 15 \mathrm{~min}$ before feeding and offered twice daily in equal meals at 09.00 and 17.00 hours. When the drinks were given an additional half meal of HEM was given through the gastric cannula at the end of the morning after gastric emptying measurements were finished.

\section{Collection of gastric digesta}

One sample was taken per pig per $d$ (Monday-Friday) in a randomized order just before or $0 \cdot 5,1,2$ or $4 \mathrm{~h}$ after the morning meal.

Most of the digesta were evacuated from the stomach using a vacuum pump. This was called the evacuated digesta. Any remaining residues were then removed by rinsing the stomach with water (called the rinses) using the method of Low et al. (1985).

\section{Analytical methods}

pH, weight of digesta and DM were measured as in previous studies (Rainbird \& Low, 1986). In addition, free glucose was measured in deproteinized digesta samples collected following consumption of GD only, using the following method: duplicate $2 \mathrm{~g}$ samples of digesta and pooled rinses were deproteinized using $4 \mathrm{ml}$ each of equimolar $(0 \cdot 3 \mathrm{M})$ zinc sulphate and barium hydroxide. The precipitated barium sulphate was removed by centrifugation for $10 \mathrm{~min}$ at $1500 \mathrm{~g}(2500 \mathrm{rev} / \mathrm{min})$ in a bench-top centrifuge (Minor; MSE Ltd, Crawley, West Sussex). The supernatant fraction was stored at $-20^{\circ}$ for subsequent glucose analysis using a glucose oxidase $(E C 1.1 .3 .4)$ - peroxidase $(E C 1.211 .1 .7)$ method (Boehringer Mannheim, Mannheim, West Germany), in an automatic analyser (AAI AutoAnalyzer; Technicon, Basingstoke, Hants).

\section{Expression of results}

$\mathrm{pH}$ values are direct measurements. The weight of digesta, DM and free glucose (GD only) remaining in the stomach at different times after feeding, less the amount in the stomach 
in the prefeed sample, are expressed as a percentage of the weight of test meal (including water), DM and free glucose intake respectively.

The half-time $\left(T_{50}\right)$ of gastric emptying was also calculated for the emptying of digesta, $\mathrm{DM}$ and free glucose from the stomach.

\section{RESULTS}

$p H$

The mean $\mathrm{pH}$ of the evacuated digesta after consumption of the test meals is shown in Table 2.

Comparison of test meals without guar gum. The $\mathrm{pH}$ of the gastric digesta rose following consumption of HEM and fell steadily with time after feeding. At $4 \mathrm{~h}$ after consumption of LEMD and GD the mean gastric $\mathrm{pH}$ had reached prefeeding values: both were significantly lower than after HEM at this time.

Comparison of test meals with guar gum. Observed differences were similar to those in the comparison of the test meals without guar gum. HEMG and LEMDG gave rise to a mean gastric $\mathrm{pH}$ which was significantly higher than GDG, both 0.5 and $1 \mathrm{~h}$ after consumption.

At $4 \mathrm{~h}$ after consumption, HEMG gave rise to a significantly higher mean gastric $\mathrm{pH}$ than LEMDG and GDG, which were not significantly different from each other by this time.

Effect of addition of guar gum to a test meal. Addition of guar gum to HEM had little effect on the mean gastric $\mathrm{pH}$ except $4 \mathrm{~h}$ after consumption when addition of guar gum to HEM had significantly raised the mean gastric pH from 3.29 to $4 \cdot 28$.

Addition of guar gum to LEMD had no statistically significant effect on gastric $\mathrm{pH}$, although the digesta with guar gum always had a slightly higher mean $\mathrm{pH}$ than the non-guar-gum meal.

In the case of GD the mean gastric $\mathrm{pH}$ was significantly raised 0.5 and $1 \mathrm{~h}$ after consumption by the addition of guar gum to the drink.

\section{Weight of digesta}

Table 2 shows the percentage of the test meal ingested remaining in the stomach. Before the morning meal there was very little digesta (or DM) in the stomach.

Comparison of test meals without guar gum. The fastest emptying rate was found for GD (with an exponential pattern) and the slowest for HEM (with a linear pattern). It is worth noting that $4 \mathrm{~h}$ after consumption only $5 \%$ of GD remained in the stomach, i.e. almost the same amount of digesta found in the prefeeding sample.

Comparison of test meals with guar gum. The pattern of emptying of the guar-gumcontaining meals was similar to that of the non-guar-gum meals. The greatest differences between the test meals were seen $4 \mathrm{~h}$ after feeding: $53 \%$ of HEMG but only $7.9 \%$ of GDG remained in the stomach at this time.

Effect of addition of guar gum to a test meal. Addition of guar gum to HEM reduced the rate of emptying of digesta from the stomach.

Addition of guar gum to LEMD had little effect on the emptying of digesta, except $2 \mathrm{~h}$ after feeding when it significantly increased the amount of digesta remaining in the stomach.

Addition of guar gum to GD had no significant effects on the emptying of digesta from the stomach.

$D M$

Table 2 shows the percentage of the DM intake remaining in the stomach.

Comparison of test meals without guar gum. After a period of rapid emptying of DM from 
Guar gum and gastric emptying of test meals

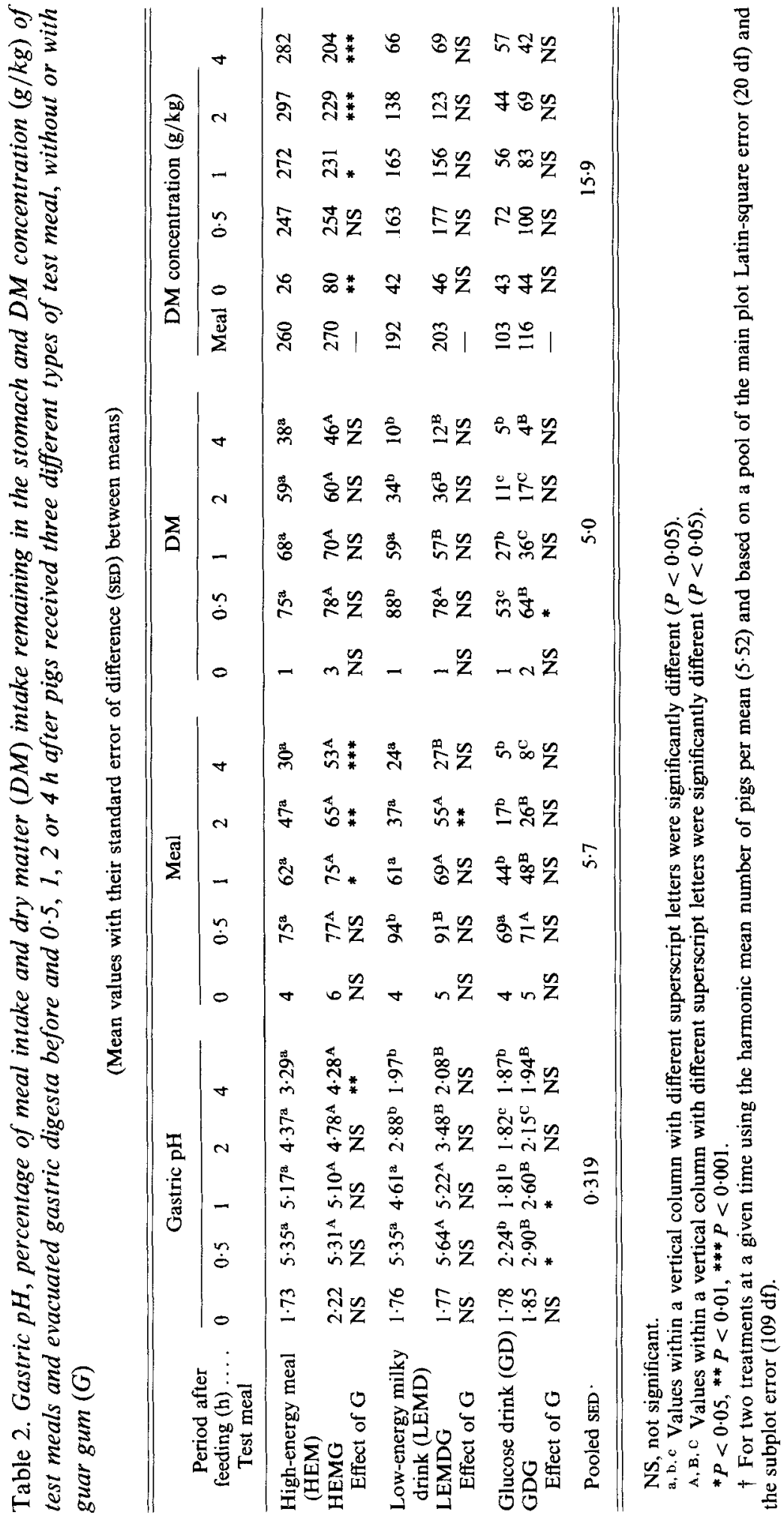


the stomach in the first 30 min following consumption of HEM, a linear pattern of DM emptying was observed. However, DM from the GD (almost entirely glucose), emptied in an exponential pattern. The pattern of emptying of LEMD was intermediate.

Comparison of test meals with guar gum. The pattern of emptying of DM from the guar-gum-containing meals was similar to that of the non-guar-gum meals.

Effect of addition of guar gum to a test meal. Addition of guar gum to either HEM or LEMD had little effect on the emptying of DM from the stomach. However, addition of guar gum to GD reduced the mean rate of emptying of DM $0 \cdot 5,1$ and $2 \mathrm{~h}$ after feeding, although this was only statistically significant $0.5 \mathrm{~h}$ after feeding. In the case of GD and LEMD, no effect of guar gum was seen $4 \mathrm{~h}$ after feeding because very little of the DM intake remained in the stomach by this time.

\section{$D M$ concentration of evacuated gastric digesta}

The DM concentration of the test meals and evacuated gastric digesta is shown in Table 2. Comparisons were only made between test meals without or with the addition of guar gum because of the large variation in the DM concentration of the test meals without guar gum.

Addition of guar gum to LEMD and GD had no significant effect on the DM concentration of the meal or of evacuated gastric digesta but the DM concentration of the evacuated gastric digesta decreased with time after consumption.

The addition of guar gum to HEM had little effect on the DM concentration of the test meal or the evacuated gastric digesta $0.5 \mathrm{~h}$ after feeding. However, $1 \mathrm{~h}$ after consumption of HEMG the DM concentration of the evacuated digesta was significantly lower than for HEM alone. This difference was even greater 2 and $4 \mathrm{~h}$ after feeding.

$$
\mathrm{T}_{50}
$$

Table 3 shows the mean time taken for half the intake of a test meal (on a weight or DM basis) to empty from the stomach.

Comparison of test meals without guar gum. The $T_{50}$ values for the emptying of digesta indicate that HEM and LEMD emptied from the stomach at a similar rate (on a percentage basis) but the emptying of GD was much faster.

However, the $T_{50}$ values for the emptying of DM suggest that the DM content of GD emptied from the stomach much faster than that from LEMD which in turn emptied faster than that from HEM.

Comparison of test meals with guar gum. The $T_{50}$ values suggest that the emptying of both digesta and DM from the stomach was fastest after GDG and slowest with HEMG.

Effect of addition of guar gum to a test meal. Addition of guar gum to each of the test meals increased the $T_{50}$ values for the emptying of digesta from the stomach but this was only significant for HEM. Expressing the results in the form of $T_{50}$ values indicates that only addition of guar gum to HEM reduced the rate of emptying of digesta from the stomach.

No significant differences were seen in the mean $T_{50}$ for the emptying of DM from the stomach when guar gum was added to the three test meals. Therefore, although addition of guar gum to HEM reduced the rate of emptying of digesta from the stomach, it had little effect on the emptying of DM.

\section{Free glucose}

Table 4 shows the effect of guar gum on the percentage of the free glucose intake which remained in the stomach. Addition of guar gum to GD significantly increased the amount of free glucose remaining in the stomach $0 \cdot 5,1$ and $2 \mathrm{~h}$ after consumption. 
Table 3. Half time $\left(\mathrm{T}_{50} ;\right.$ min $)$ for the emptying of digesta and dry matter from the stomach after pigs received three different types of test meal, without or with guar gum $(G)$

(Mean values with their standard errors of differences (SED) between means)

\begin{tabular}{lcc}
\hline \multicolumn{1}{c}{ Test meal } & Digesta & Dry matter \\
\hline High-energy meal (HEM) & $123^{\mathrm{a}}$ & $169^{\mathrm{a}}$ \\
HEMG & $259^{\mathrm{A}}$ & $195^{\mathrm{A}}$ \\
Effect of G & $4 * *$ & $\mathrm{NS}$ \\
Low-energy milky drink (LEMD) & $103^{\mathrm{a}}$ & $78^{\mathrm{b}}$ \\
LEMDG & $133^{\mathrm{B}}$ & $78^{\mathrm{B}}$ \\
$\quad$ Effect of G & $\mathrm{NS}$ & $\mathrm{NS}$ \\
Glucose drink (GD) & $52^{\mathrm{b}}$ & $31^{\mathrm{c}}$ \\
GDG & $60^{\mathrm{C}}$ & $46^{\mathrm{C}}$ \\
Effect of G & $\mathrm{NS}$ & $\mathrm{NS}$ \\
Pooled SED & 23.5 & 14.7 \\
\hline \hline
\end{tabular}

NS, not significant.

a, b, c Values within a vertical column with different superscript letters were significantly different $(P<0.05)$.

A, B, C Values within a vertical column with different superscript letters were significantly different $(P<0.05)$.

*** $P<0.001$.

Table 4. Percentage of free glucose intake remaining in the stomach just before or $0.5,1$, 2 or 4 h after pigs received glucose drinks without $(G D)$ or with guar gum (GDG)

(Mean values and standard error of difference (SED) between means)

\begin{tabular}{lcccccc}
\hline \hline & \multicolumn{5}{c}{ Period after feeding (h) } \\
\cline { 2 - 6 } & Test meal & 0 & $0 \cdot 5$ & 1 & 2 & 4 \\
\hline GD & 0 & 52 & 25 & 6 & 1 \\
GDG & 0 & 63 & 39 & 18 & 6 \\
& NS & $*$ & $*$ & $*$ & NS \\
\hline
\end{tabular}

Pooled SED 4.8.

NS, not significant.

$* P<0.05$.

The $T_{50}$ for the emptying of free glucose was significantly increased by the addition of guar gum to GD, from 30 to $49 \mathrm{~min}$.

\section{DISCUSSION}

\section{Technique}

A simple gastric cannulation technique was used in the present study for the reasons discussed by Low et al. (1985).

The initial evacuation by suction removed most of the digesta (before any rinsing was done) after consumption of the test meals, without or with guar gum. Digesta removed by this method should therefore be representative of the whole gastric contents.

\section{$p H$}

The postprandial gastric $\mathrm{pH}$ profiles for the HEM were similar to those observed in previous experiments (Rainbird \& Low, 1986). GD resulted in a markedly different postprandial pH profile from that following both the HEM and LEMD; this might have been due in part to 
the lack of buffering effect of protein (GD contained no protein). The low $\mathrm{pH}$ value recorded before all morning meals and $4 \mathrm{~h}$ after consumption of LEMD and GD corresponded with the time when the stomach contained little more than gastric secretions, of approximately $\mathrm{pH} 2$.

Addition of guar gum to the meals generally increased the $\mathrm{pH}$ of the gastric digesta at each postprandial sampling time. These differences may have been a consequence of reduced acid secretion by the stomach but this was not measured in the present study. It is also possible that guar gum buffers the secreted acid. The changes in $\mathrm{pH}$ may also be a consequence of differences in rate of emptying of digesta observed in the present study between meals without or with guar gum but since the emptying of DM (which contains protein to buffer the acid) is not altered by guar gum, this may not be the most important factor involved. However, these explanations remain speculative because there have been no other studies in which the gastric $\mathrm{pH}$ profiles after different test meals or after the addition of guar gum to a meal have been compared in any species.

\section{Digesta}

It is clear that major differences between different types of test meal existed in the emptying of digesta (and DM) from the stomach.

The mean emptying rate in the $4 \mathrm{~h}$ after consumption of HEM was greater than in previous experiments in this series using the same basal diets (Rainbird \& Low, 1986). It was also more rapid than observed in pigs, using similar methods, by Cuber et al. (1980) who fed a diet of $(\mathrm{g} / \mathrm{kg}): 820$ maize starch, 150 protein supplement, 30 cellulose. This was surprising because the high-fat content of the HEM in the present experiment might have been expected to reduce the rate of emptying of digesta. However, the explanation for the difference between the present results and those of Cuber et al. (1980) may lie in the diet : water value used which was $1: 2.5$ in the present experiment but only $1: 1(\mathrm{w} / \mathrm{v})$ in that of Cuber et al. (1980). This is supported by Low et al. (1985) who found that digesta emptying rose as water intake (varying between 1.75 and 3.25 times DM intake) increased, although DM emptying remained unaffected.

The very slow emptying of LEMD compared with HEM in the first 30 min after feeding might have been due to the difference in the volumes of meal ingested. It has been shown that the rate of liquid emptying $(\mathrm{ml} / \mathrm{min})$ is faster when larger volumes are ingested both in man (Hunt \& Spurrell, 1951) and in the pig (Low et al. 1985). However, the percentages of the intakes emptied from the stomach 0.5-4 h after consumption of HEM and LEMD were similar but, because of the difference in the volume of meal ingested, the actual volumes of digesta emptied into the duodenum were quite different.

The overall pattern of gastric emptying of GD in the present study being exponential in nature corresponds well with the observations in man by Hunt \& Spurrell (1951) who also used a simple liquid test meal. After the differences in the rate of emptying in the first hour following consumption of GD and LEMD, similar rates of emptying $(\mathrm{ml} / \mathrm{min})$ were observed. Since 1 litre of each drink was consumed, the early differences in the rate of emptying were not due to differences in volume consumed, but to other physiological differences induced by the composition of the drinks: it seems likely that the fat and protein contents of LEMD were responsible in part at least for its slower initial rate of gastric emptying than that of GD.

The similarities in the patterns of emptying of digesta from HEM and LEMD were reflected in similar $T_{50}$ values (Table 3). The lower $T_{50}$ for GD than for the other meals was because of its very rapid emptying in the first hour after the meal. Using $T_{50}$ values to study differences in the gastric emptying of meals can thus mask important but subtle changes between meals (e.g. in the first hour after feeding, HSM v. LEMD (Table 2)) or 
similarities (1-4 h after feeding, LEMD and GD (Table 2)). If a reduction in the rate of gastric emptying is an important factor in reducing postprandial hyperglycaemia when guar gum is added to the meal, the difference must be seen during the first hour after feeding since this is the period when the major reduction in hyperglycaemia occurs (Jenkins et al 1978; Sambrook \& Rainbird, 1985). The use of $T_{50}$ values will not indicate this.

The addition of guar gum to HEM caused the greatest percentage reduction in the rate of emptying of digesta. Since the rate of emptying of DM from the stomach was similar following consumption of the HEM and HEMG, differences observed in the emptying of digesta were due to differences in the emptying of liquid. This cannot be entirely attributed to the water-holding capacity of guar gum because similar concentrations of guar gum we e added to HEM ( $24 \mathrm{~g} / \mathrm{kg}$ water as fed) and GD (20 g/l water). It is unlikely that the difference was due to an increase in gastric secretion following the addition of guar gi $\mathrm{m}$ to the meal since guar gum was associated with increases in the $\mathrm{pH}$ of the digesta.

The present measurements of gastric emptying in pigs did not show an effect of guar gum on the gastric emptying of digesta, i.e. the sum of the liquid and solid fractions, after consumption of LEMD. This is in contrast to the studies of Wilmshurst \& Crawley (1980) who found a significant increase in 'mean gastric transit time' in obese human subjects from 69 to 112 min when guar gum was added to LEMD. However, Wilmshurst \& Crawley (1980) used a method of measuring the emptying of liquid only from the stomach by labelling the meal with ${ }^{24} \mathrm{Na}$; changes in radioactivity measured using a sodium iodide crystal round the head of the subject were used as a measure of gastric emptying. This indirect method depends on the rapid absorption of $\mathrm{Na}$ in the proximal small intestine after emptying from the stomach. Since previous experiments in vivo in both rats (Blackburn \& Johnson, 1981) and pigs (Rainbird et al. 1984) have shown that the rate of absorption of glucose from the small intestine is reduced by the addition of guar gum, it seems possible that the delay in the appearance of ${ }^{24} \mathrm{Na}$ in head blood was due to a delay in intestinal absorption rather than to a reduction in the rate of gastric emptying.

\section{$D M$}

The pattern of emptying of DM after consumption of HEM in the present study was very similar to that observed by Cuber et al. (1980) even though a different diet : water value was used. This finding is supported by the study of Low et al. (1985) who showed that water intake (varying between 1.75 and 3.25 times DM intake) did not have a marked effect on the emptying of DM from the stomach of pigs given a cereal-based diet, although digesta emptying rates rose as water intakes increased.

The emptying of DM was more rapid after consumption of GD than of the other test meals. It followed an exponential pattern rather than the linear pattern usually observed with DM emptying (Heading et al. 1976), probably because the DM consisted only of glucose which was dissolved in the liquid.

An important point to note is the fact that $2 \mathrm{~h}$ after consumption of GD and $4 \mathrm{~h}$ after consumption of the LEMD only $10 \%$ of the DM intake remained in the stomach. Since the emptying of these meals was almost complete in this time, caution needs to be exercised in extrapolating the results to normal meal feeding with its longer gastric emptying times.

As observed in previous experiments in pigs (Rainbird \& Low, 1986), addition of guar gum to the HEM had no effect on the emptying of DM from the stomach. The effect of adding guar gum to HEM has not been studied in humans.

Addition of guar gum to LEMD also had no effect on the emptying of DM but as the method used by Wilmshurst \& Crawley (1980) only measured liquid emptying, direct comparisons cannot be made.

However, the addition of guar gum to GD significantly reduced the emptying of DM 
$0.5 \mathrm{~h}$ after consumption, i.e. at the time when the flattening of the postprandial blood-glucose curve by guar gum is seen in man (Jenkins et al. 1978) and pigs (Rainbird et al. 1986) after consumption of a similar drink. Although the $T_{50}$ value for the emptying of DM after GD was increased by guar gum, the difference was not significant. This is another example of how $T_{50}$ values may lead to erroneous interpretation of gastric emptying patterns, since an important and significant increase in the amount of DM remaining in the stomach was seen $0.5 \mathrm{~h}$ after feeding.

From these results it can be concluded that the beneficial reduction in postprandial hyperglycaemia observed when guar gum is added to a meal does not appear to be due to a reduction in DM emptying from the stomach when meals of moderate or high DM content are used, but gastric emptying of DM may play a role when meals of very-low DM content are used.

\section{Glucose}

The reduction in the rate of emptying of free glucose from the stomach in the present experiment (Table 4) is consistent with the results of Leeds et al. (1979) who found the $T_{50}$ value for the emptying of glucose after a high-viscosity meal was significantly longer than after a low-viscosity meal (41 and 16 min respectively), using different guar gum preparations to achieve differences in viscosity. These results support the previous conclusion that changes in the pattern of gastric emptying are probably of importance in reducing postprandial hyperglycaemia when guar gum is added to meals of very-low DM content.

\section{DM concentration of evacuated gastric digesta}

Since there were marked differences in the emptying of digesta after HEM without or with guar gum but no differences in the DM flow, it was clear that there would be differences in the DM content of the digesta (Table 2). These may have been due to a difference in the contribution of secretions (salivary and gastric) or a difference in the emptying of liquid from the stomach. The latter possibility seems to be the most likely because guar gum was associated with increases rather than decreases in gastric $\mathrm{pH}$ (implying no increase in acid secretion). This is also supported by the observation that the DM in HEM settled rapidly on the bottom of a beaker when left to stand on a bench, whereas HEMG remained homogeneous. A more rapid emptying of the liquid phase compared with the solid phase has also been observed in human studies, e.g. Heading et al. (1976).

\section{Conclusions}

The results of the present study show that major differences exist in the emptying of digesta and DM from the stomach between relatively-liquid test meals often used in human studies and HEM usually eaten by man or by pigs. This is attributable to the small volume and soluble nature of the DM in the human test meals compared with much larger meals of largely insoluble matter which are fed to pigs or normally eaten by man.

Differences observed between the previous experiments on gastric emptying in pigs (Rainbird \& Low, 1986) and rats (Leeds et al. 1979) appear to have been due to differences in the type of test meal used in the studies. The differences between the results of the present study and that of Wilmshurst \& Crawley (1980) seem likely to be due to differences in the technique used to measure gastric emptying rather than different responses by the two species.

The results suggest that guar gum does not modify the pattern of gastric emptying of DM from a HEM, although it reduced the rate of emptying of the liquid fraction of the digesta. Thus gastric emptying does not appear to be the only mechanism involved in the reduction of postprandial hyperglycaemia when added to a HEM. In addition, guar gum did reduce the rate of DM emptying from meals of very-low DM content and therefore 
in these cases gastric emptying may be important in determining postprandial hyperglycaemia. It must be stressed, however, that meals of this type are of diagnostic rather than of nutritional importance.

The author would like to thank Dr A. G. Low for his advice and encouragement during the course of this study, Dr I. E. Sambrook for the surgery, Mr A. R. Jones and his staff for care of the animals, Mr H. A. Smith for technical assistance and Mrs R. J. Elliott for statistical advice. A.L.R. gratefully acknowledges receipt of an Agricultural Research Council Postgraduate Research Studentship. The guar gum was kindly donated by $\mathrm{Mr}$ R. M. W. Hopkins of Meyhall Chemical (UK) Ltd.

\section{REFERENCES}

Blackburn, N. A. \& Johnson, I. T. (1981). British Journal of Nutrition 46, 239-246.

Cuber, J.-C., Laplace, J.-P. \& Villiers, P. A. (1980). Reproduction, Nutrition, Développement 20, 1161-1172.

Heading, R. C., Tothill, P., McLoughlin, G. P. \& Shearman, D. J. C. (1976). Gastroenterology 71, 45-50.

Hunt, J. N. \& Spurrell, W. R. (1951). Journal of Physiology 113, 157-168.

Jarjis, H. A., Blackburn, N. A., Redfern, J. S. \& Read, N. W. (1984). British Journal of Nutrition 51, 371-378.

Jenkins, D. J. A., Wolever, T. M. S., Leeds, A. R., Gassull, M. A., Haisman, P., Dilawari, J., Goff, D. V., Metz, G. L. \& Alberti, K. G. M. M. (1978). British Medical Journal i, 1392-1394.

Leeds, A. R., Bolster, N. R., Andrews, R. \& Truswell, A. S. (1979). Proceedings of the Nutrition Society 38, 44 A. Low, A. G., Pittman, R. J. \& Elliott, R. J. (1985). British Journal of Nutrition 54, 437-447.

Rainbird, A. L., Ellis, P. R., Morris, E. R. \& Low, A. G. (1986). Proceedings of the XIII International Congress of Nutrition (In the Press).

Rainbird, A. L. \& Low, A. G. (1986). British Journal of Nutrition 55, 87-98.

Rainbird, A. L., Low, A. G. \& Zebrowska, T. (1984). British Journal of Nutrition 52, 489-498.

Sambrook, I. E. \& Rainbird, A. L. (1985). British Journal of Nutrition 54, 27-35.

Wilmshurst, L. P. \& Crawley, J. C. W. (1980). British Journal of Nutrition 44, 1-6. 